ARTICLE

https://doi.org/10.1038/s41467-019-09421-5

\title{
Optimising surface $d$ charge of AuPd nanoalloy catalysts for enhanced catalytic activity
}

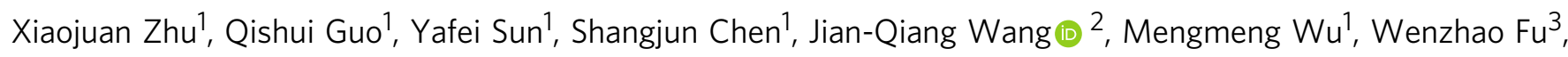
Yanqiang Tang ${ }^{3}$, Xuezhi Duan ${ }^{3}$, De Chen ${ }^{4} \&$ Ying Wan (1) ${ }^{1}$

Understanding the catalytic mechanism of bimetallic nanocatalysts remains challenging. Here, we adopt an adsorbate mediated thermal reduction approach to yield monodispersed AuPd catalysts with continuous change of the Pd-Au coordination numbers embedded in a mesoporous carbonaceous matrix. The structure of nanoalloys is well-defined, allowing for a direct determination of the structure-property relationship. The results show that the $\mathrm{Pd}$ single atom and dimer are the active sites for the base-free oxidation of primary alcohols. Remarkably, the $d$-orbital charge on the surface of Pd serves as a descriptor to the adsorbate states and hence the catalytic performance. The maximum $d$-charge gain occurred in a composition with 33-50 at\% Pd corresponds to up to 9 times enhancement in the reaction rate compared to the neat $\mathrm{Pd}$. The findings not only open an avenue towards the rational design of catalysts but also enable the identification of key steps involved in the catalytic reactions.

\footnotetext{
${ }^{1}$ Key Laboratory of Resource Chemistry of Ministry of Education, Shanghai Key Laboratory of Rare Earth Functional Materials, and Department of Chemistry, Shanghai Normal University, Shanghai 200234, China. ${ }^{2}$ Shanghai Synchrotron Radiation Facility, Shanghai Institute of Applied Physics, Chinese Academy of Sciences, Shanghai 201204, China. ${ }^{3}$ State Key Laboratory of Chemical Engineering, East China University of Science and Technology, Shanghai 200237, China. ${ }^{4}$ Department of Chemical Engineering, Norwegian University of Science and Technology, Trondheim N-7491, Norway. These authors contributed equally: Xiaojuan Zhu, Qishui Guo and Yafei Sun. Correspondence and requests for materials should be addressed to Y.W. (email: ywan@shnu.edu.cn)
} 
B imetallic catalysts, for example gold-palladium, have been widely applied in aerobic oxidation of primary alcohols, direct synthesis of $\mathrm{H}_{2} \mathrm{O}_{2}$, etc ${ }^{1-3}$. Their catalytic properties are largely governed by the surface electronic structure of transition metals. So far, exploring the effects of the electronic properties on the catalytic performance for alloys is focused on the cutting of well-defined surfaces of bulk alloys or vapour deposition of a metal onto a single-crystal face of the second metal. The determined model alloy structure facilitates the investigation of the alloy effects on the enhancement for the activity and selectivity. Ensemble and ligand effects have been primarily concerned to mirror the properties of surface alloys; that is, the formation of a contiguous palladium domain when diluting a finite amount of $\mathrm{Pd}$ with $\mathrm{Au}$, and the charge transfer between $\mathrm{Au}$ and $\mathrm{Pd}$ or orbital rehybridization of $\mathrm{Au}$ due to the heteroatom bonds ${ }^{4-6}$. Substantial efforts have been devoted to identifying a descriptor for the target reactions. In particular, the $d$-band centre relative to the Fermi level, in which the calculated average energy of the projected density of states for the model metal surface $d$-states can be linked to the interaction with adsorbate states and hence the catalytic performance ${ }^{5,7}$. However, the synergistic effects observed in the experiments using the bimetallic NPs are not always directly correlated to their surface alloy counterpart ${ }^{8}$. Obviously, the electronic properties and in turn the adsorption for substrates are closely dependent on the nature of the alloy and if it has a eutectic-like or core-shell structure $^{8}$. Motivated by the success of the $d$-band centre theory as the activity descriptor for metal surfaces, as well as the transition from single-crystal studies to more industrially relevant catalysts, we are seeking a simple and experimentally measurable descriptor that quantitatively correlates the surface electronic structure to the catalytic activity for transition metal nanoalloy catalysts.

We take advantage of the flexibility of the physical and chemical properties of the gold-palladium alloy which have complete miscibility to experimentally examine alloys with continuous concentration of $\mathrm{Pd}$ to establish the catalytic properties for the industrially relevant reactions involving strong adsorbates. The thermodynamically stable configuration is an $\mathrm{Au}_{\text {shell }} \mathrm{Pd}_{\text {core }}$ configuration because of the high segregation energy of $\mathrm{Au}$ in $\mathrm{Pd}^{8,9}$. The encapsulation of active Pd surface with a relatively inactive Au shell would inhibit the activity in Pd-catalyzed reactions. Hutchings and co-workers first reported that a Au-rich-core/Pd-shell structure on $\mathrm{TiO}_{2}$ can be kinetically generated at low temperatures and show high activity in selective oxidation ${ }^{1}$. However, this arrangement is theoretically predicted to undergo a transition to the above thermodynamically stable core-shell reversal above $500 \mathrm{~K}^{8,10}$. Great efforts have been made to obtain compositionally uniform AuPd nanoalloys and the activity can benefit ${ }^{11-13}$. Unfortunately, the bimetallic structures generally suffer from a dynamical structure change during the liquid phase reactions in particular strongadsorbate-involved processes due to the metal segregation, leaching and re-deposition ${ }^{14}$. Breaking through the thermodynamic favourable structures of bimetallic nanoparticles is a goal that has been long sought after ${ }^{15,16}$, to obtain both the determined structural resolution with the continuously tuning for the metal ligands of the surface, and the high-efficient and stable catalysts with targeted site requirements for sustainable chemical synthesis.

Herein, we provide a direct experimental evidence for the measured $d$ charge at surface Pd sites in AuPd nanoparticles as a descriptor, which correlates well with the catalytic activities, with a typical example for the base-free oxidation of primary alcohols. As a consequence, the unambiguous identification of the site requirements for the formation of targeted oxidation products can be resolved. This is based on the stable monodispersed AuPd nanoalloys with determined structural resolution at an atomic level supported on a less-active carrier which can minimize metal oxide interactions, as well as particle size and compositional uniformity effects. The maximum in the $d$-charge gain has been found with $33-50$ at $\% \mathrm{Pd}$ and results in the highest reaction rate for the oxidation of alcohols. The finding represents a very important advance not only for the rational design of catalysts but also for the identification and tracking of key steps involved in the catalytic reactions.

\section{Results}

Microstructural properties of Au-Pd nanoalloy. The representative $\mathrm{Au}$ and $\mathrm{Pd}$ line profiles of the energy-dispersive X-ray spectroscopy (EDX) spectra in the scanning transmission electron microscopy (STEM) mode for the $\mathrm{Au}_{67} \mathrm{Pd}_{33}, \mathrm{Au}_{50} \mathrm{Pd}_{50}$ and $\mathrm{Au}_{33} \mathrm{Pd}_{67}$ particles match well from the periphery to the centre. These results indicate that these bimetallic catalysts have uniform compositions throughout the particles, which quantitatively match with the synthesis ratios used within $10 \%$ (Fig. 1a, Table 1, Supplementary Figs. 1-4) ${ }^{17}$. Further analysis by EDX mapping in the TEM mode and X-ray photoelectron spectroscopy (XPS) measurements confirm that the Au:Pd ratios are close to the theoretical ones (Supplementary Figs. 5 and 6, Table 1). The TEM images of the bimetallic catalysts predominantly show well-distributed, isolated nanoparticles inside hexagonally arranged mesopores, and the nanoparticles have an average size of approximately $3.0 \mathrm{~nm}$ regardless of the metal compositions (Supplementary Fig. 7). The images of an ultrathin section of $\mathrm{Au}_{50} \mathrm{Pd}_{50}$ are quite similar to those of the above bulk catalyst, further confirming that the metal nanoparticles are intercalated into the mesopores instead of coating the outer surface of the carbon supports (Fig. 2). Aggregation of nanoparticles and their subsequent migration to the outer surface are hindered even at a high carbonization temperature of $600^{\circ} \mathrm{C}$. Interestingly, semiexposure nanoparticles can be clearly observed. In addition, the spherical aberration corrected-STEM (AC-STEM) images for fresh $\mathrm{Au}_{50} \mathrm{Pd}_{50}$ show uniform nanoparticles with approximate size of $2.9 \mathrm{~nm}$ in large domains and negligible sub-nanometre metal clusters can be found (Fig. 2). Thus, the possibility for the activity contribution from the sub-nanometre clusters can be ruled out. Typical type-IV nitrogen sorption isotherms are observed for all studied catalysts, which are characteristic of open mesoporous solids with uniform pore sizes (Supplementary Fig. 8, Table 1). These phenomena indicate that metal nanoparticles do not show an obvious effect on the mesoporous structure.

The $k^{3}$-weighted and Fourier transformed extended X-ray absorption fine structure (EXAFS) spectra of the AuPd nanoparticles near the Pd K-edge and $\mathrm{Au} \mathrm{L}_{3}$-edge are shown in Fig. 1b. Compared to the monometallic Pd catalyst, the AuPd bimetallic catalysts exhibit a dramatically reduced signal attributable to the Pd-Pd bond even with a low Au-to-Pd ratio. A new peak appears at a longer distance, which is primarily attributed to the $\mathrm{Au}-\mathrm{Pd}$ bond $^{18}$. The enhanced intensity of this peak with increasing Au content shows the gradual increase in the number of Au-Pd bonds in these nanocatalysts, which provides additional information regarding the formation of the alloy structure. Note that the $\mathrm{Pd}-\mathrm{O}$ contribution is a major factor in Pd-rich catalysts and the lack of a major feature from $\mathrm{Pd}-\mathrm{O}-\mathrm{Pd}$ for $\mathrm{Pd}$ oxides essentially excludes the formation of oxides. When the Au-to-Pd ratio exceeds 2 , the backscattering from $\mathrm{Pd}-\mathrm{Pd}$ and $\mathrm{Pd}-\mathrm{O}$ almost disappears. This phenomenon suggests that contiguous $\mathrm{Pd}$ clusters disappear with increased Au loading; isolated Pd domains form, and eventually each Pd atom is separated by an Au atom, forming isolated Pd single atoms at Pd-diluted nanoalloys ${ }^{4,19,20}$. Both core-shell and eutectic structures can thus be also excluded as the causes for this phenomenon ${ }^{21}$. 

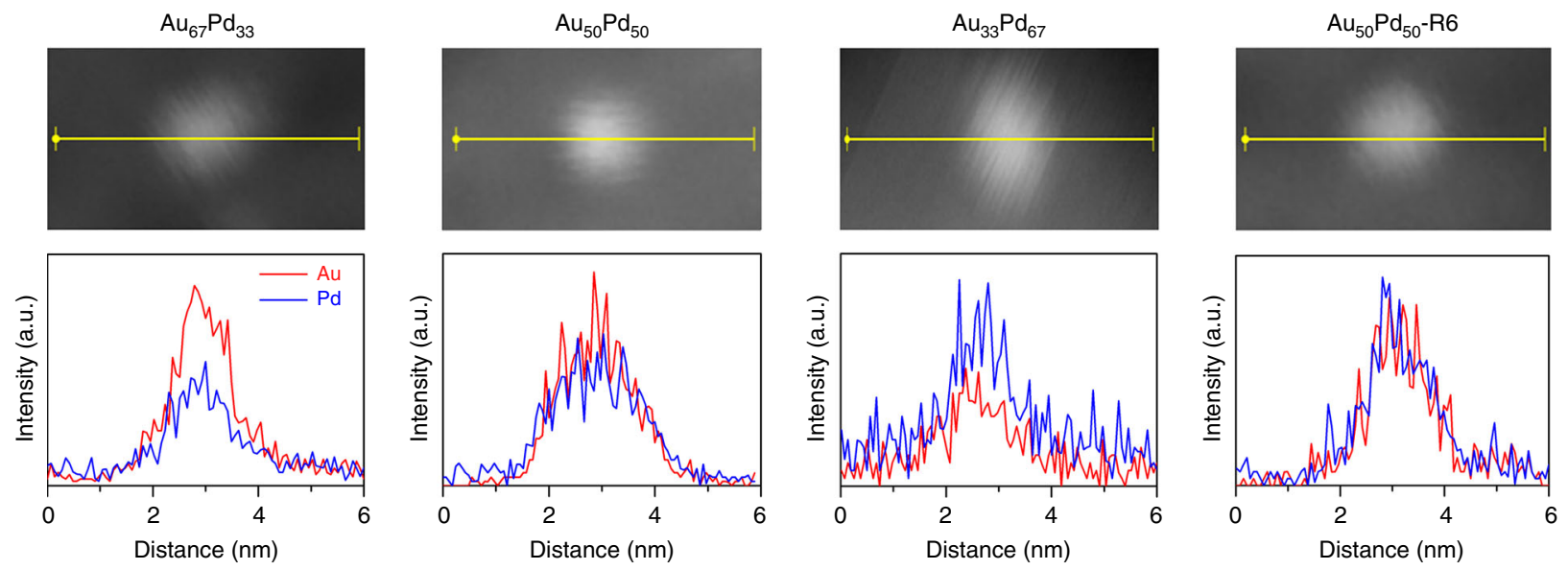

b
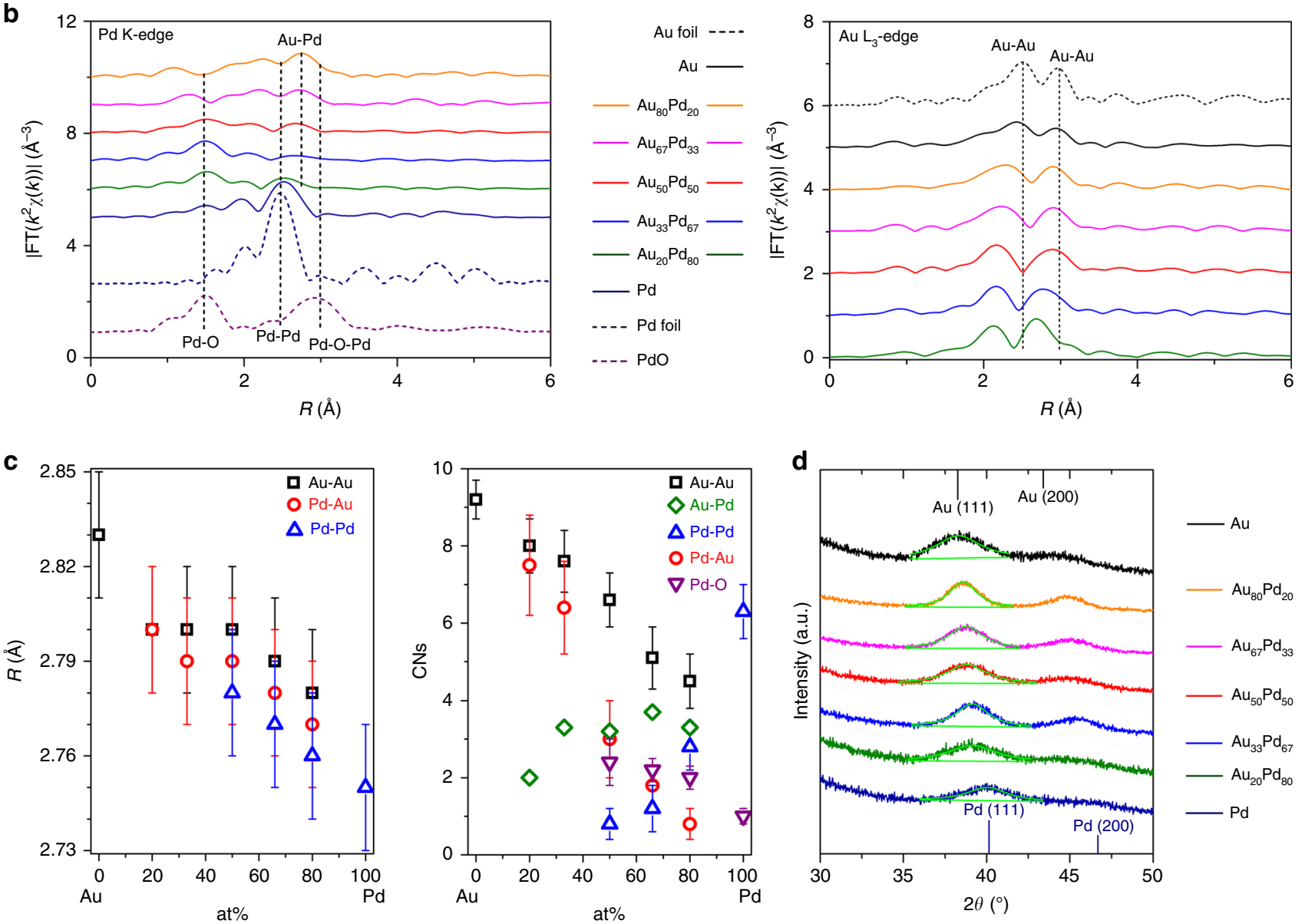

Fig. 1 Microstructural characterization. a Representative line profiles of the EDX patterns of a single particle of the nanoalloys collected using a focused electron beam in the sub-nanometre range in the STEM mode. $\mathbf{b} k^{3}$-weighted and Fourier transformed magnitudes of the EXAFS spectra $\left(\left|F T\left(k^{2} \chi(k)\right)\right|\right)$ of the Pd K-edge and $\mathrm{Au} \mathrm{L}_{3}$-edge of the nanoalloy and monometallic catalysts along with the reference metal foils and metal oxide. The Fourier transforms were not corrected for phase shifts. c Fourier transformed EXAFS fitting results of the bond distance $(R)$ and the metal-metal coordination numbers (CNs) for the AuPd nanoalloys and monometallic nanoparticles. Error bars represent standard deviation. d WAXRD patterns with fine scans containing higher statistics collected near the diffraction peak at $\sim 39^{\circ}$

The typical spectral features due to the $\mathrm{Au}-\mathrm{Au}$ first-shell backscattering contributions in the AuPd bimetallic catalysts shift even with a low Pd loading, and the peaks are broadened compared to how they appear in the spectra of monometallic gold, implying that the Au-Pd backscattering impacts these features ${ }^{21}$. The $\mathrm{Au}-\mathrm{Au}$ bond distance decreases from $2.83 \AA$ in pure gold to $2.80 \AA \AA$ in Au-rich alloys. A further lattice contraction is observed for Au-diluted nanoalloys, suggesting the presence of very small $\mathrm{Au}$ clusters ${ }^{22}$. The interatomic distances follow an order of $\mathrm{Au}-\mathrm{Au}>\mathrm{Au}-\mathrm{Pd}(\mathrm{Pd}-\mathrm{Au})>\mathrm{Pd}-\mathrm{Pd}$, as shown in Fig. 1c. The Pd-Pd scattering distance in the AuPd nanoalloys increases with increasing gold content and is comparable to the interatomic distance for Au-Pd. These results suggest the presence of a welldefined Au-Pd phase ${ }^{23}$. 
Table 1 Structural and textural properties of the confined AuPd nanoalloy catalysts

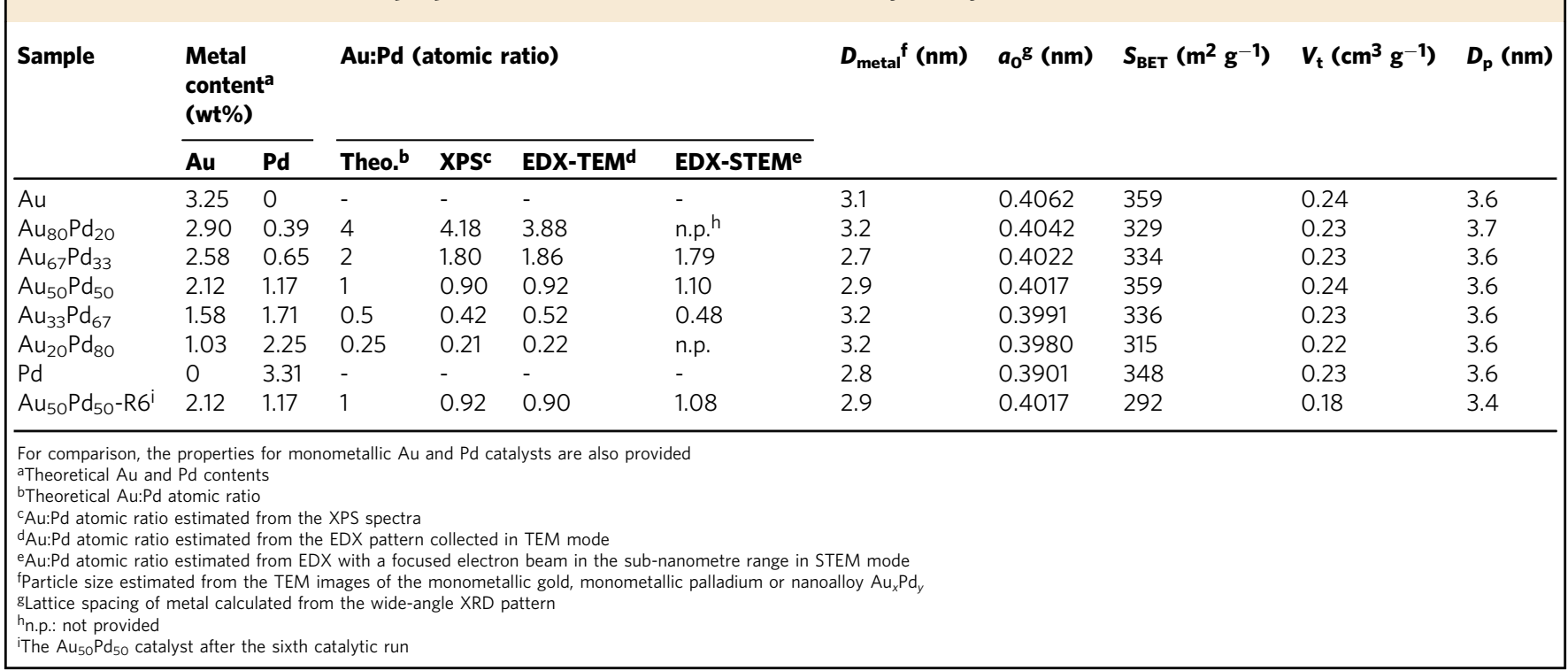

a
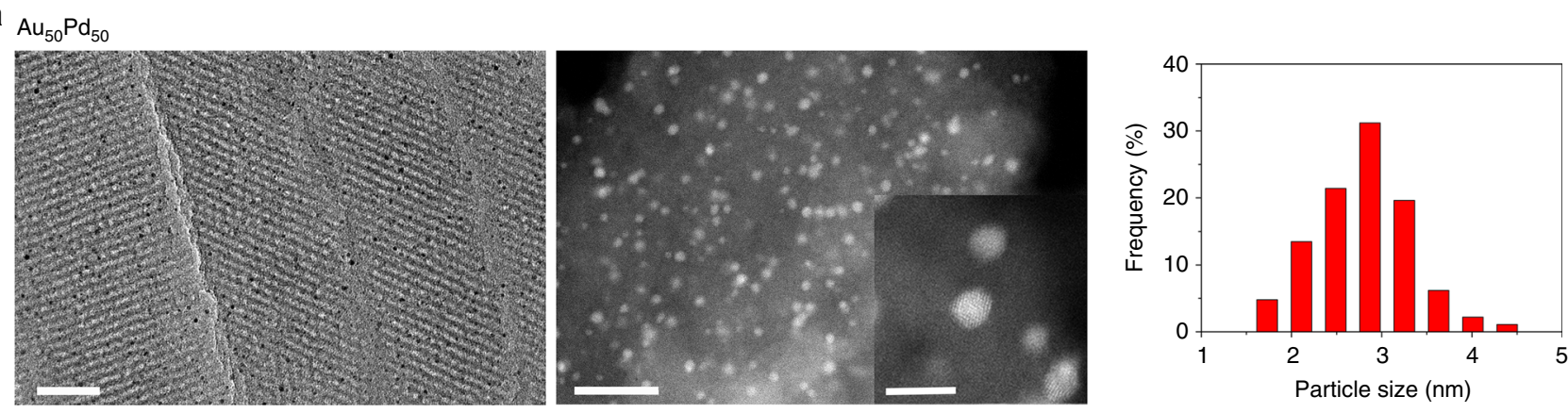

b $\mathrm{Au}_{50} \mathrm{Pd}_{50}-\mathrm{R} 6$
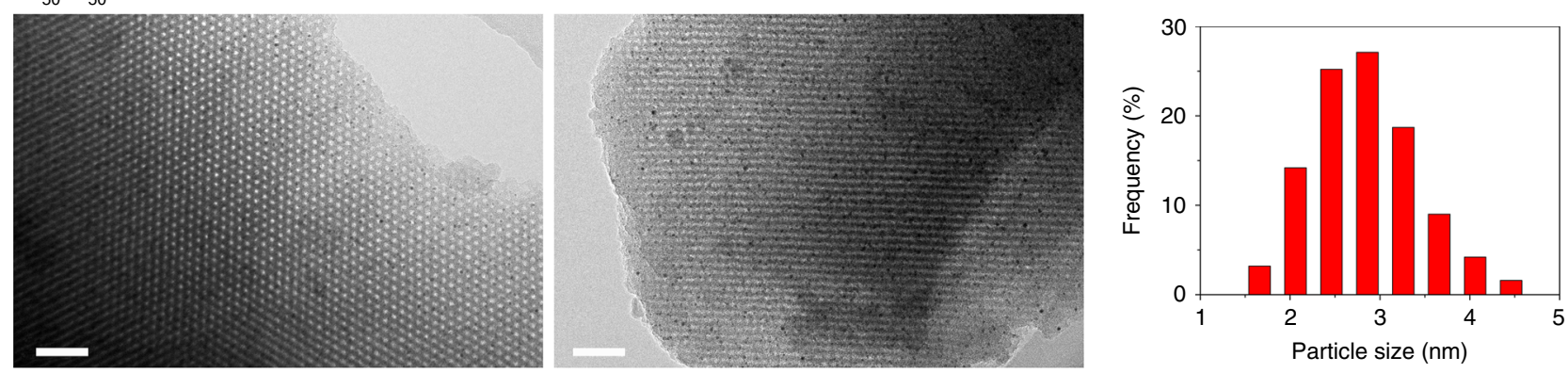

Fig. 2 TEM micrographs. a Representative TEM image of the ultrathin sections (Left, the scale bar of $50 \mathrm{~nm}$ ) and AC-STEM image (Middle, the scale bar of $20 \mathrm{~nm}$ ) for the fresh $\mathrm{Au}_{50} \mathrm{Pd}_{50}$. Inset Middle figure is the AC-STEM image with a high magnification, and the scale bar is $5 \mathrm{~nm}$. $\mathbf{b}$ TEM images of the recycled $\mathrm{Au}_{50} \mathrm{Pd}_{50}-\mathrm{R} 6$ after six catalytic runs viewed along the [001] and [110] directions. The scale bar is $50 \mathrm{~nm}$. Particle size distributions (Right (a) and (b)) were determined with at least 200 nanoparticles

At the low percentage of $\mathrm{Pd}(<50 \%)$, the coordination number $(\mathrm{CN})$ of $\mathrm{Pd}-\mathrm{Pd}$ is zero and the $\mathrm{CN}$ of $\mathrm{Pd}-\mathrm{Au}$ increases with reducing $\mathrm{Pd}$ percentage (Fig. 1c), suggesting an atomic dispersion of $\mathrm{Pd}$ in the $\mathrm{Au}$ matrix. When the percentage of $\mathrm{Pd}$ is $50 \%$, the $\mathrm{CN}$ of $\mathrm{Pd}-\mathrm{Pd}$ is about 1 , where $\mathrm{Pd}$ exists dominantly as $\mathrm{Pd}$ dimer ${ }^{24}$. At the high loading of $\mathrm{Pd}(>50 \%)$, with increasing $\mathrm{Pd}$ percentage, the $\mathrm{CN}$ of $\mathrm{Au}-\mathrm{Au}$ is not zero but decreases, while the $\mathrm{CN}$ of Pd-Pd increases exponentially; simultaneously, the $\mathrm{CN}$ of $\mathrm{Pd}-\mathrm{Au}$ sharply decreases and the $\mathrm{CN}$ of $\mathrm{Au}-\mathrm{Pd}$ is a relative constant. It suggests that the $\mathrm{Au}$ is not atomically distributed and prefers in the existence of small islands. The ratio of CNs for the $\mathrm{Pd}$ clusters ( $\mathrm{Pd}-\mathrm{Pd}$ and $\mathrm{Pd}-\mathrm{O}$ coordination) to that of $\mathrm{Pd}-\mathrm{Au}$, is close to the $\mathrm{Pd} / \mathrm{Au}$ ratio, which further implies that the alloy is random. The observation is in good agreement with the density functional theory (DFT) prediction by Nørskov and coworkers $^{25}$. The segregation and mixing energy of $\mathrm{Au}-\mathrm{Pd}(0.15$ $\mathrm{eV}$ for Au-host and $-0.14 \mathrm{eV}$ for Pd-host alloys) suggest that $\mathrm{Pd}$ thermodynamically prefers a random-distribution, while $\mathrm{Au}$ prefers a segregation and exists as small islands in the alloy with the Au-host ${ }^{10}$. 
The wide-angle X-ray diffraction (WAXRD) patterns show similar diffraction peaks for all catalysts regardless of their compositions (Supplementary Fig. 9). The symmetric diffraction peaks at approximately $39^{\circ}$ imply the presence of a nanoalloy instead of a monometallic core-shell structure or macroscopic phase separation (Fig. 1d). This peak in the spectra of the bimetallic catalysts is clearly shifted compared to where it appears for monometallic $\mathrm{Au}$ and Pd. In fact, for the bimetallic catalysts, this peak is located between where it appears for either the monometallic $\mathrm{Au}$ or Pd species, which is the evidence for the formation of an alloy ${ }^{26}$.

Electronic properties. The X-ray absorption near-edge structure (XANES) spectrum of the $\mathrm{Au} \mathrm{L}_{3}$-edge of the monometallic $\mathrm{Au}$ nanocatalyst shows a less intense white line than that of $\mathrm{Au}$ foil (Fig. 3) ${ }^{27}$. The further diminishment of white line intensity may result from either the presence of $\mathrm{Pd}$ in the enhanced filling of the $\mathrm{Au} d$-band or the reduction in the $\mathrm{Au}-\mathrm{Au}$ coordination number ${ }^{22}$. However, the white line intensity almost remains unchanged for all studied alloy catalysts. A substantial enhancement in the intensity of the post-edge feature is observed, when the Pd content increases, which is related to an increase in the number of available $d$ states above the Fermi level ${ }^{28}$. This change can be attributed to the effect of the bimetallic distance, which causes the intra-atomic redistribution of charge or in other words, the decrease of the Au $5 d$ electron states upon being alloyed with $\operatorname{Pd}^{27,29}$.

The hybridization-mediated $1 s \rightarrow 4 d, d p(a)$ absorption transition in the pre-edge region is not resolved in the spectra of monometallic Pd nanocatalyst and Pd foil. However, the first inflection point of the edges occurs on an expanded energy scale, implying the change in the oxidation state of the metal. The postedge threshold is shifted to a slightly higher energy; this may be due to the presence of tiny Pd particles with a Pd metal $f c c$ structure with very short range order and/or the coordination of $\mathrm{Pd}$ with a light $\mathrm{O}$ atom ${ }^{30}$. When the Pd nanoparticles are diluted with 20 and $33 \mathrm{at} \% \mathrm{Au}$, the white line energy position further shifts to higher energies in nearly identical fashion with the absorption edge as $\mathrm{PdO}$, which is in agreement with the increase of $\mathrm{Pd}-\mathrm{O}$ coordination. The $1 s \rightarrow 5 p(p)$ transition shifts to an even higher energy and the signal broadens. This shift can be interpreted as an electronic perturbation of the Pd atoms going from a Pd-like environment in the monometallic structure to the AuPd alloy phase. The Pd $d$-band becomes occupied ${ }^{6}$. A negative shift in the $1 s \rightarrow 4 f(f)$ transition accompanied by a significant reduction in intensity is detected, which reflects the increase in the atomic distance and $4 d-5 p$ hybridization ${ }^{31,32}$. Similar phenomena have been observed for local distortions of the Pd lattice by interstitial $\mathrm{C}^{31}$ and $\mathrm{AuPd}^{33}$ bimetallic nanoparticles. The above shifts are poorly resolved in the spectra of $\mathrm{Au}_{50} \mathrm{Pd}_{50}$, implying that the $4 d$ band is filled. With further dilution with $\mathrm{Au}$ atoms, both the white line and thresholds of the $\mathrm{Au}_{x} \mathrm{Pd}_{y}$ catalysts shift towards those observed for Pd foil, indicating a change in the orbital character of the screening charge ${ }^{34}$. The $\mathrm{Au}_{80} \mathrm{Pd}_{20}$ sample shows the most intense metallic Pd features in which the Pd-Pd and $\mathrm{Pd}-\mathrm{O}$ bonds cannot be detected. Isolated $\mathrm{Pd}$ atoms in the $\mathrm{Au}$ aggregates can be demonstrated.

The typical doublets for the Au $4 f$ XPS spectra can be deconvoluted, and the major peaks for $\mathrm{Au}^{0}$ (85.7\%) in all $\mathrm{Au}$ containing catalysts can be fitted (Fig. 4). Compared to the monometallic Au catalyst, the Au $4 f$ core levels of the AuPd nanoalloys show a gradual negative shift towards a lower binding energy as the Pd loading increases. The doublets for the Pd $3 d$ core bands of the monometallic Pd catalyst can be deconvoluted into three phases; the major peak fitted can be assigned to metallic Pd, a minor peak can be attributed to $\mathrm{Pd}-\mathrm{O}$ coordination ${ }^{35}$, which comes from the carbonyl, carboxyl, hydroxyl groups in carbon carrier or oxygen in air, and an extremely weak peak can be attributed to O-Pd-O coordination (not discussed here). As the Pd loading decreases, a gradual negative shift is observed for AuPd nanoalloys due to the Au-Pd alloy interaction. A relatively large shift is observed for the Pd-diluted alloys. Interestingly, the $\mathrm{Au}_{80} \mathrm{Pd}_{20}$ nanoparticles show a less intense peak from the $\mathrm{Pd}-\mathrm{O}$ bond. This result indicates that diluted Pd atoms in an Au host are much more stable in air. The negative shifts of both the Au $4 f$ and Pd $3 d$ core level bands in bimetallic species compared to the corresponding monometallic species have been also reported for bulk AuPd alloys ${ }^{36}$, in contrast to $\mathrm{Cu}-\mathrm{Pd}$ bulk alloys ${ }^{37}$, where the $\mathrm{Pd}$ shifts are positive and the $\mathrm{Cu}$ negative. Models in which the redistribution of occupied valence shells is caused by a difference in the hybridization of Pd and Au appear quite reasonable ${ }^{38,39}$.
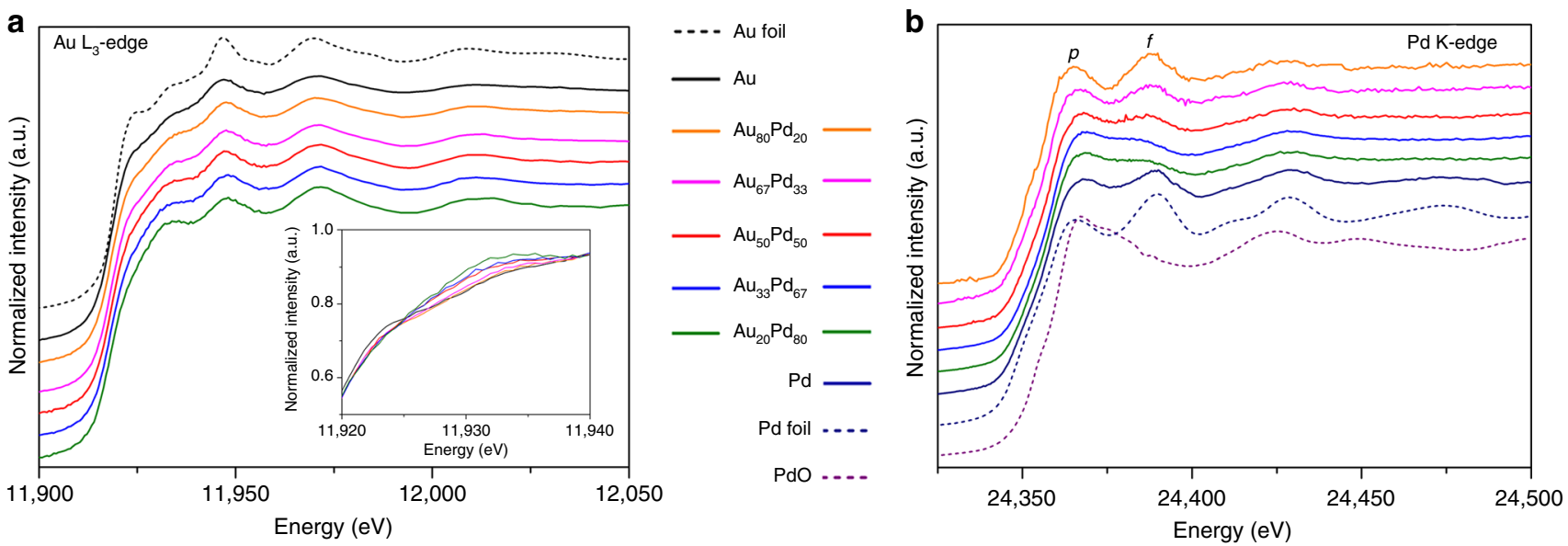

Fig. 3 Electronic properties of the AuPd nanoalloys measured by XANES spectroscopy. a The XANES spectra of the Au $L_{3}$-edge of monometallic Au, AuPd nanoalloys and reference Au foil. $\mathbf{b}$ The XANES spectra of the Pd K-edge of monometallic Pd, AuPd nanoalloys and reference Pd foil and PdO. The Pd XANES spectrum at the K-edge of the Pd foil exhibited a pronounced white line due to the unfilled Pd $d$-band, and the spectrum of PdO exhibited an even more obvious white line that shifted to a higher threshold energy because of the higher oxidation state of Pd in PdO. The hybridization-mediated $1 s \rightarrow 4 d$, $d p(a)$ absorption transition in the pre-edge region was unresolved. The near-edge spectrum showed two resonance peaks that are due to the $1 s \rightarrow 5 p(p)$ and $1 s \rightarrow 4 f(f)$ transitions through hybridization. The shape of the second absorption edge reflected the extent of the $4 d-5 p$ hybridization. This feature was insignificant in the spectrum of the PdO reference 

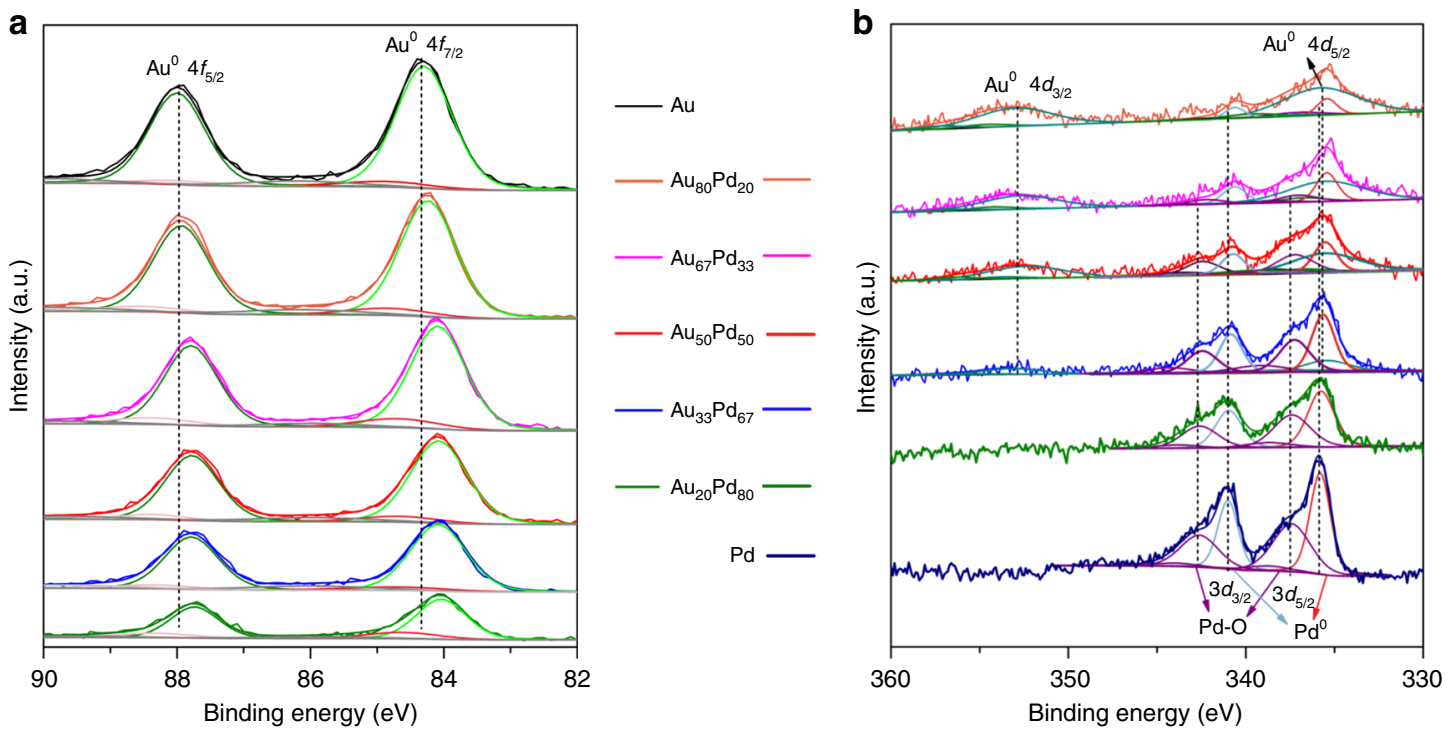

Fig. 4 Surface compositions and electronic properties. a XPS spectra of the $4 f$ level of Au. $\mathbf{b}$ XPS spectra of the $3 d$ level of Pd. The Au and Pd binding energies were fitted by peak fitting techniques. Metallic $\mathrm{Au}$, metallic $\mathrm{Pd}$ and $\mathrm{Pd}-\mathrm{O}$, which were the dominant contributors to each spectrum, were discussed. A distinct overlap could be observed between the Pd $3 d_{5 / 2}$ and the Au $4 d_{5 / 2}$ components for the bimetallic catalysts. The Au $4 d_{5 / 2}$ intensity was calculated from the well-resolved $\mathrm{Au} 4 d_{3 / 2}$ intensity, and this value was subtracted from the above overlapped peak to determine the Pd $3 d_{5 / 2}$ intensity. The resulting value was used to calculate the Au:Pd ratio

The $d$ band is active in alloying; the non- $d$-charge flows onto an Au site is largely compensated by accompanying Au $d$ charge depletion; the net charge flow is small. The detailed discussion is shown in the following part on combination with the XAFS results.

Kinetics analysis and DFT calculations. The aerobic oxidation of primary alcohols in an aqueous solution in the absence of base is used as a model reaction here because this is a strong-adsorbateinvolved reaction and Pd-involving sites are more active than the $\mathrm{Au}$ case on a carbon support ${ }^{40}$. The neat Pd catalyst results in a low conversion and fast deactivation. The complete oxidation of benzyl alcohol (BA) to $\mathrm{CO}_{2}$ and the depletion of $\mathrm{O}_{2}$ can be excluded. Therefore, the switching-off for the neat Pd catalyst is possibly due to the strong adsorption of produced aldehyde and acid on the surface. Our results have also shown the content of products generated in the Au-catalysed oxidation of the selected primary alcohols is below the limit of detection, similar to the gold sols loaded on activated carbon catalyst ${ }^{41}$. It should be mentioned that the studied carbon support serves as a lessactive support ${ }^{42}$, and the gold nanoparticles are not able to extract the hydride from the alcoholic function. Once the base is present, the alcoholate can be formed in solution, and the oxidation activity can be significantly improved ${ }^{41,43-45}$. While alloying a small amount of Pd ( $\mathrm{Au}: \mathrm{Pd}=4)$ with the Au NPs yields oxidative products, e.g. the BA conversion approaches $12 \%$ at $4 \mathrm{~h}$ (Fig. 5).

The leaching of dissolved metal ions is firstly excluded. A solid containing an unprotected thiol was used to poison the possible soluble metallic species in BA oxidation ${ }^{46}$. Results show no significant differences in the turn-over frequency (TOF) values of any of the AuPd nanoalloys in the presence/absence of mercaptofunctionalized ordered mesoporous silica (SH-SBA-15). It confirms the negligible Pd leaching into solutions (Supplementary Fig. 10). After six catalytic runs using $\mathrm{Au}_{50} \mathrm{Pd}_{50}$, both the $\mathrm{BA}$ conversions in the initial phase of the reaction and at the end of the reaction show no substantial changes, and only a slight increase is observed for the initial conversion (Supplementary Fig. 11). The collected solution after each run shows undetected metal ions. The TEM images of the recycled $\mathrm{Au}_{50} \mathrm{Pd}_{50}$ nanocatalyst are quite similar to those of the fresh catalyst, and show invisible nanoparticle aggregation (Fig. 2). The EDX mapping spectra give the $\mathrm{Au}$ and Pd concentration of 2.18 and $1.32 \mathrm{wt} \%$, respectively, similar to that determined for the fresh catalyst (2.15 and $1.27 \mathrm{wt} \%$, respectively), further excluding the leaching of metal into solutions. The estimated Au:Pd ratios based on the XPS analysis, XRD patterns or the representative EDX line profiles in the STEM mode (Fig. 1, Supplementary Table 1 and Fig. 12) are almost the same as that in the fresh catalyst, indicating the surface segregation of Pd or Au can be excluded. The pore volumes slightly decrease, possibly because organic residue is deposited inside the mesopores (Table 1 and Supplementary Fig. 8). These results indicate the mesostructure and heterogeneous AuPd alloy nanocatalysts are stable, and negligible leaching occurs even during repeated reactions involving strong adsorbates. The leaching-resistance feature during reactions even involving S-containing substances has also been found in the nanoparticles inside mesoporous carbon ${ }^{43,47}$. This can guarantee the investigation of surface catalysis and almost unchanged surface Pd concentrations after reaction.

Decreasing the $\mathrm{Au} / \mathrm{Pd}$ ratios to 2 and 1 results in increments of the BA conversions to 26 and $42 \%$ at $4 \mathrm{~h}$, respectively. However, the BA conversion does not improve on further increasing the Pd concentration. The reduction of BA conversion to approximate $21 \%$ is observed for $\mathrm{Au}_{20} \mathrm{Pd}_{80}$. For a rigorous comparison, the selectivity was compared restraining the similar BA conversions. Only benzaldehyde is detected in the initial period. With an increase in the conversion, the only by-product of benzoic acid is produced. Other byproducts such as toluene and benzyl benzoate are undetected, analogous to the results over supported AuPd nanocatalysts reported by Prati and co-workers ${ }^{41}$. The formation of the byproducts is very sensitive to the reaction conditions and catalyst used. For example, toluene is one of the main byproducts in the solvent-free $\mathrm{BA}$ oxidation at a relatively high temperature $\left(>120^{\circ} \mathrm{C}\right)$ possibly via the disproportionation of $\mathrm{BA}^{1}$, but is seldom detected in the water-mediated reaction ${ }^{41}$. The concentration variations of components with time conform to the regularity of the consecutive reaction. The transformation to 


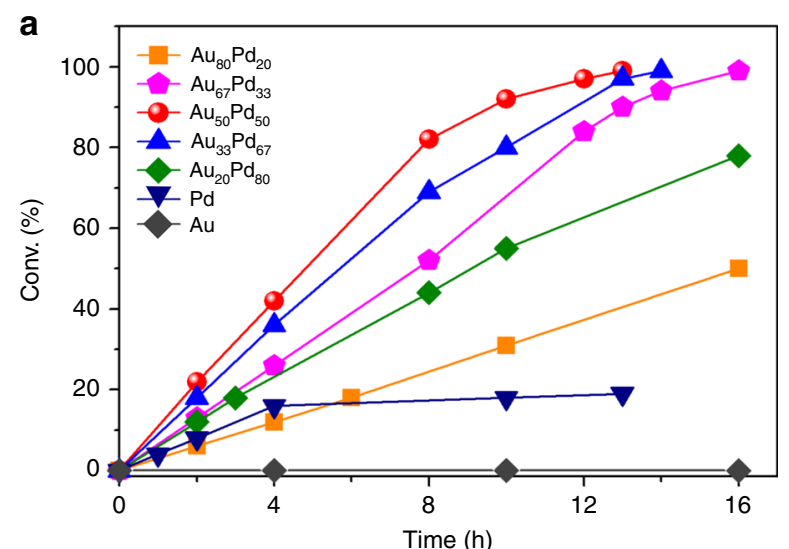

C

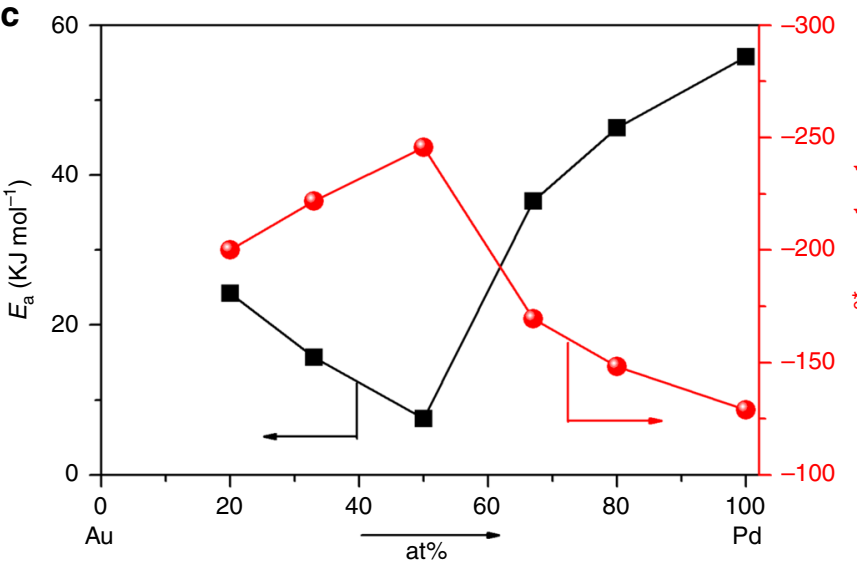

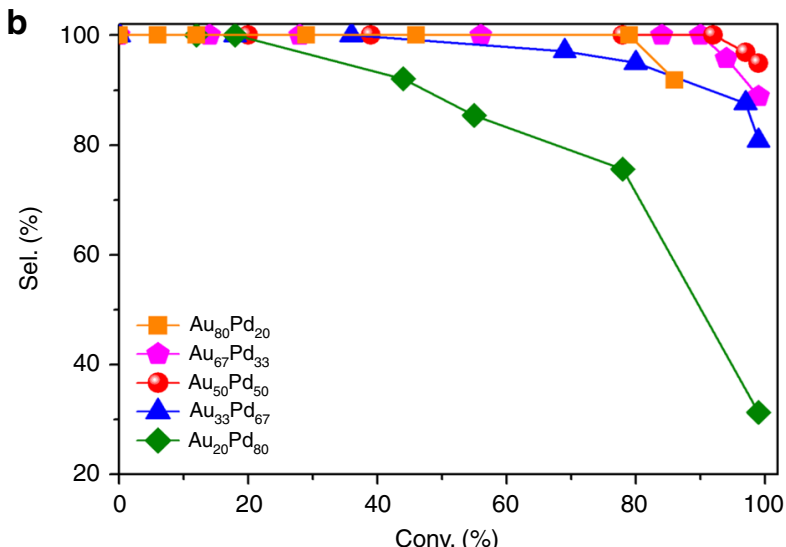

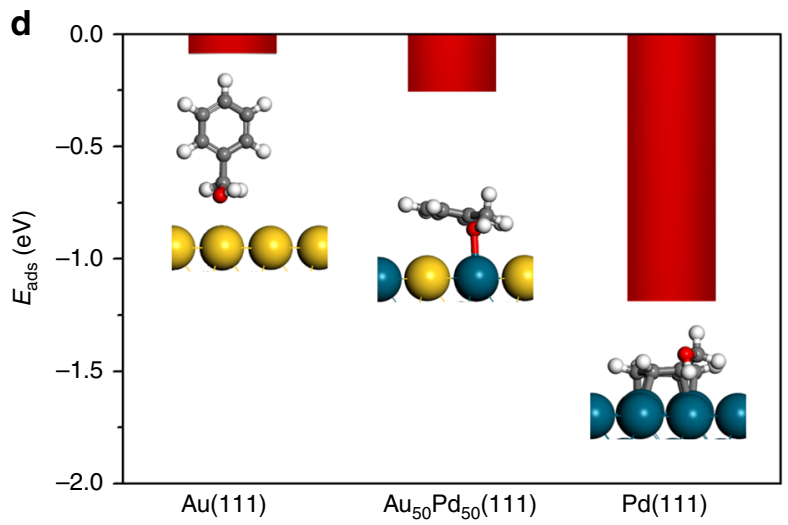

Fig. 5 Kinetics analysis and DFT calculations. a Benzyl alcohol conversion (Conv.) as a function of time with the following reaction conditions over

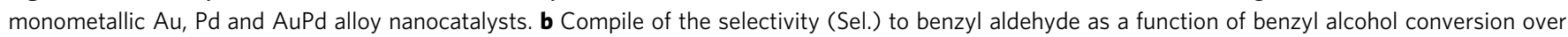
AuPd alloy nanocatalysts. c Relationship between the activation energy $\left(E_{a}\right)$ and entropy of activation ( $\Delta S^{0^{\star}}$ ) for the oxidation of benzyl alcohol to benzaldehyde on the AuPd alloys as a function of concentration. $\mathbf{d}$ The most favourite configuration and the adsorption energy ( $E_{\text {ads }}$ ) of benzyl alcohol over

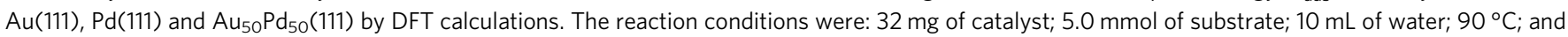
in the presence of oxygen by an $\mathrm{O}_{2}$ balloon under atmospheric pressure

the by-product is also highly related to the Pd concentration in the nanoalloy catalysts. We observed that the $\mathrm{Au}_{50} \mathrm{Pd}_{50}$ and $\mathrm{Au}_{67} \mathrm{Pd}_{33}$ catalysts also exhibit the highest selectivity under a high conversion (above 90\%). The decrease in the Pd loading slightly decreases the selectivity. The over oxidation occurs at a conversion of $\sim 80 \%$ for $\mathrm{Au}_{80} \mathrm{Pd}_{20}$. On contrary, the overloading of $\mathrm{Pd}$ in nanoalloys results in a dramatic reduction of selectivity. The by-product of benzoic acid can be detected with a BA conversion of 69 and $44 \%$ over $\mathrm{Au}_{33} \mathrm{Pd}_{67}$ and $\mathrm{Au}_{20} \mathrm{Pd}_{80}$, respectively.

Preliminary experiments indicated the absence of diffusion limitations and mass transfer effect under present reaction conditions (Methods, Supplementary Fig. 13). The approximate constants of reaction rates along with the given BA concentration ranges would suggest the reaction orders for BA is Pseudo zero order (Supplementary Fig. 14). In addition, the studied catalysts show almost Pseudo zero-order reaction kinetics during the initial period of the reaction. The reaction constant $\left(k_{\mathrm{Pd}}\right)$ can be deduced. Arrhenius plots are presented in Supplementary Fig. 15, where the apparent activation energies $\left(E_{\mathrm{a}}\right)$ and the preexponential factors $(A)$ were estimated. The apparent entropies changes $\left(\Delta S^{0^{*}}\right)$ for the nanoalloy catalysts were also estimated based on transition state theory. The activation energies follow a reverse volcano-shaped curve while $\Delta S^{0^{*}}$ follows a volcano-like curve as a function of the Pd percentage as shown in Fig. $5 c$, and the maximum $\Delta S^{0^{*}}$ and minimum $E_{\mathrm{a}}$ are observed for the 50 at $\%$
Au catalyst. A linear relationship between $E_{\mathrm{a}}$ and $\Delta S^{0^{*}}$ has been observed (Supplementary Fig. 16), which is called the compensation effect, due to the changed bonds between the surface atoms and the adsorbates ${ }^{48}$.

The estimated turn-over frequency on the basis of exposed Pdinvolving sites $\left(\mathrm{TOF}_{\mathrm{Pd}}\right)$ was taken to eliminate the effect of $\mathrm{Au}$ dilution (Supplementary Fig. 16). Volcano-type behavior was observed for $\mathrm{TOF}_{\mathrm{Pd}}$ when going from pure $\mathrm{Au}$ to pure $\mathrm{Pd}$ (Supplementary Fig. 17), and the maximum TOF was achieved with $\mathrm{Au}_{67} \mathrm{Pd}_{33}$ and $\mathrm{Au}_{50} \mathrm{Pd}_{50}$ showing $\sim 9$ times higher than the neat $\mathrm{Pd}$ catalyst, which is characteristic of structure-sensitive reactions ${ }^{49}$. The $\mathrm{TOF}_{\mathrm{Pd}}$ values for the Pd-diluted catalysts are much higher than the case of Pd-rich catalysts. Similar results have been observed for selective oxidation of primary alcohols, including 4-methylbenzyl alcohol, 4-anisalcohol and phenethyl alcohol.

Periodic DFT calculations were performed on the adsorption of $\mathrm{BA}$ on $\mathrm{Au}_{50} \mathrm{Pd}_{50}(111), \mathrm{Pd}(111)$ and $\mathrm{Au}(111)$ surfaces at low coverage (Fig. 5d, Supplementary Table 2 and Figs. 18-20). The most favourite adsorption configuration for BA on $\mathrm{Pd}(111)$ is that the phenyl of BA parallels and strongly interacts with the $\operatorname{Pd}(111)$ surface, while hydroxyl group tilts away from the surface. Different studies agree with that $\mathrm{BA}$ oxidation proceeds through a benzyl alkoxide $\left(\mathrm{PhCH}_{2} \mathrm{O}-\right)$ intermediate to adsorbed benzaldehyde ${ }^{44,50-52}$. The bond scission sequence is $\mathrm{O}-\mathrm{H}$ followed by $\mathrm{C}^{\alpha}-\mathrm{H}$. The surface adsorbed $\mathrm{HO}^{*}$ or $\mathrm{HOO}^{\star}$ species promotes the 
elimination of $\mathrm{C}^{\alpha}-\mathrm{H}$, which is considered as the rate-determining step. Accordingly, the weak activation of the $\mathrm{O}-\mathrm{H}$ bond and the coverage of the phenyl functions which could poison the $\mathrm{Pd}$ surface are the possible reasons for the inhibition of dehydrogenation and in turn activity. In addition, this process is different with the methane oxidation using $\mathrm{H}_{2} \mathrm{O}_{2}$ as the oxidant, in which the hydroxyl radicals (HO.) from the homolytic cleavage of the $\mathrm{HO}-\mathrm{OH}$ bond can oxidize methanol to $\mathrm{HCOOH}$ and $\mathrm{CO}_{2} 53,54$. On contrary, the chemical bonding between the $\mathrm{Au}(111)$ surface and the functional group of hydroxyl and phenyl group is negligible. Therefore, the $\mathrm{Au}$ surface is not able to extract the hydride from the alcoholic function when supported on lessactive porous carbons and behaves inert in BA oxidation. The chemisorption of BA on the AuPd(111) surface through hydroxyl group shows an evidently enhanced adsorption energy compared to the parallel adsorption via aromatic ring. As a result, it directly activates the $\mathrm{OH}$ group in $\mathrm{BA}$, and facilitates the further dehydrogenation.

\section{Discussion}

An adsorbate mediated reduction is responsible for the formation of AuPd nanoalloys with tuneable hybridization and heterometallic bond distances. We monitored the preparation of the catalysts. The ultraviolet-visible (UV-Vis) diffuse reflectance spectroscopy shows that ligand exchange is converting $\mathrm{Au}-\mathrm{Cl}$ and $\mathrm{Pd}-\mathrm{Cl}$ coordination to $\mathrm{Au}-\mathrm{S}$ and $\mathrm{Pd}-\mathrm{S}$ species in the mother solutions (Supplementary Fig. 21) The temperature-programmed decomposition-mass spectrometry (TPDe-MS) measurements (Supplementary Fig. 22) present that the decomposition of resins can occur at elevated temperatures, and the sulfur is released in the form of $\mathrm{SO}_{2}$ which provides an opportunity for homogeneous mixing of $\mathrm{Au}$ and $\mathrm{Pd}$ species at atomic level to generate the AuPd nanoalloys. Simultaneously, $\mathrm{CO}$ gas is released to create the reducing atmosphere for the reduction of the metal precursors. The breakthrough of the $\mathrm{Au}-\mathrm{S}$ and $\mathrm{Pd}-\mathrm{S}$ bonds at a temperature above $220^{\circ} \mathrm{C}$ is accompanied with the reduction of metals and the condensation of the silicate-carbonaceous framework. The particles are confined by the rigid silica-carbon hybrid framework, homogenously disperse in the matrix, and show high stability even under a reductive atmosphere at $600^{\circ} \mathrm{C}$. The almost complete elimination of sulfur is observed for all catalysts based on EDX and XPS measurements, which could guarantee the excluding of the additional ligand effects. On the other hand, the gases $\left(\mathrm{CO}\right.$ and $\left.\mathrm{SO}_{2}\right)$ also facilitate the formation of surface enrichment of $\mathrm{Pd}$ rather than thermodynamically stable $\mathrm{Au}-$ segregated surface. This is mainly attributed to the preferential adsorption of $\mathrm{CO}$ on the $\mathrm{Pd}$ atoms compared to Au because of the much stronger binding of Pd with CO. Mariscal et al. ${ }^{55}$ reported that the pre-adsorption of $\mathrm{CO}$ can easily cause a structural transformation from a Pd core and an Au shell to an Au core and a Pd shell. All of these analyses indicate that our developed reduction method can breakthrough the thermodynamic limitation to generate the AuPd nanoalloys against thermodynamically favourable $\mathrm{Au}$ rich surfaces by means of the unique adsorbate induction.

The unambiguously determined alloy structure at atomic level can be used to determine the $d$ charge at $\mathrm{Pd}$ site as a function of alloy composition ${ }^{56}$. The binding energy shift, $\Delta E_{\mathrm{B}}$, is related to the changes in the one-electron energy, the change in the work function, and the final-state relaxation of a core hole between the metal and the alloy. Accordingly, non- $d$ - and $d$-charge transfer onto the atom site can be estimated based on the XPS and XANES results (Supplementary Table 3$)^{57}$. For the Pd-rich alloy, the amount of the charge transfer is in general very small upon alloying, almost less than 0.1 electrons in alloys, and the total charge transfer at Pd site is smaller than the change of $d$ electron number. The Au atoms appear to gain 0.1-0.2 sp electrons, compensated by a loss of about the same number of $d$ electrons ${ }^{36}$. The intra-atomic charge transfer is more important than the interatomic charge transfer between $\mathrm{Pd}$ and $\mathrm{Au}$ atoms. The maximum $d$-charge gain at approximate 50 at $\% \mathrm{Pd}$ alloy composition with $\mathrm{Pd}$ dimer structure results in a pronounced change in the available electronic energy states. With a further reduction in the Pd concentration, where the isolated Pd single atoms are formed, the net charge between $\mathrm{Au}$ and Pd dramatically enhances. But the $d$-electron number reduces to some extent. The $5 s p$ electron of the surface Pd atoms may lose some $d$-character due to the isolated $\mathrm{Pd}$ atoms and the coordination with $\mathrm{Au}$, which have increasing Pd-Pd bond distances. The $d$ - $d$ separation would narrow the $4 d$ band of the surface Pd sites effectively pushing the top of this band below the Fermi level. This trend in the $d$-band filling is consistent with that of the AuPd bulk alloy ${ }^{58}$. Theoretical calculations support this conclusion ${ }^{34,59}$. The 33 at $\% \mathrm{Pd}$ alloy adapting a single atom structure exhibits a similar $d$-charge gain with the 50 at $\%$ Pd alloy. While the 20 at\% Pd alloy shows a decreased $d$ electron numbers. The $d$ charge of single atom decreases with increasing its coordination number with Au. Therefore, the single atom and dimer of Pd distributed in the inert $\mathrm{Au}$ matrix can be identified as the active sites $24,60-63$. In addition, the catalytic activity and selectivity depends on the coordination of $\mathrm{Pd}$ to $\mathrm{Au}$ atom or more likely its electronic properties in nanoalloy.

The measured apparent entropy change is the difference between the entropy of the transition state and the reactant. The value reflects the freedom loss of the species due to the adsorption on the surface, more precisely the adsorption strength ${ }^{64}$. The activation entropy change would be correlated with the density of states close to the Fermi level of the transition metals, which show great effect on the bound state for the absorbed intermediate ${ }^{65}$. We therefore attempt to relate the $d$-charge gain to the activation entropy, $\Delta S^{0^{*}}$ (Fig. 6). The entropy change indeed follows a linear relationship with the $d$ charge at the Pd sites. This result indicates that the Pd charge of the Group VIII-IB nanoalloy is fundamental to the activation entropy associated with the adsorbate binding strength in the surface reaction. The increase in the reaction rate achieved with the nanoalloy (isolated or dimer of $\mathrm{Pd}$ in $\mathrm{Au}$ clusters) would be expected based on the increase in $\Delta S^{0^{*}}$, which is related to the stronger adsorption strength ${ }^{66}$. The bound state for $\mathrm{PhCH}_{2} \mathrm{O}$ over $\mathrm{Au}_{50} \mathrm{Pd}_{50}$ is therefore much favourable for catalytic dehydrogenation. Accordingly, the $d$ charge at surface Pd site can serve as a descriptor, which can correlate well with the activities (Fig. 6). The linear relationship can also be followed for other primary alcohols oxidation including 4-methylbenzyl alcohol, 4anisalcohol and phenethyl alcohol.

The maximum in the $d$-charge gain is found on Pd single atom and dimer with about 33-50 at\% Pd. The slight increase of the $\mathrm{TOF}_{\mathrm{Pd}}$ value in the repeated use may also reflect the change of $\mathrm{Pd}$ charge originated from the adsorbed oxygen-containing compounds over the used catalyst. Simultaneously, the adsorption configuration over $\mathrm{Au}_{50} \mathrm{Pd}_{50}, \mathrm{Au}_{67} \mathrm{Pd}_{33}$ and $\mathrm{Au}_{80} \mathrm{Pd}_{20}$ with $\mathrm{Pd}$ dimer and single atoms separated by $\mathrm{Au}$ atoms may hinder the disproportionation of two BA molecules to give benzaldehyde and toluene, and therefore enhances the selectivity at high conversions compared to literatures ${ }^{1}$. In addition, the improved adsorption strength of BA may inhibit the adsorption of benzaldehyde and the consecutive oxidation to benzoic acid. The selectivity to benzaldehyde is significantly enhanced at high conversions. It has been reported that the absolute thermoelectric power, $S$, of AuPd alloys is highly sensitive to the presence of unoccupied $d$-band states ${ }^{58}$. As expected, the trends are similar 

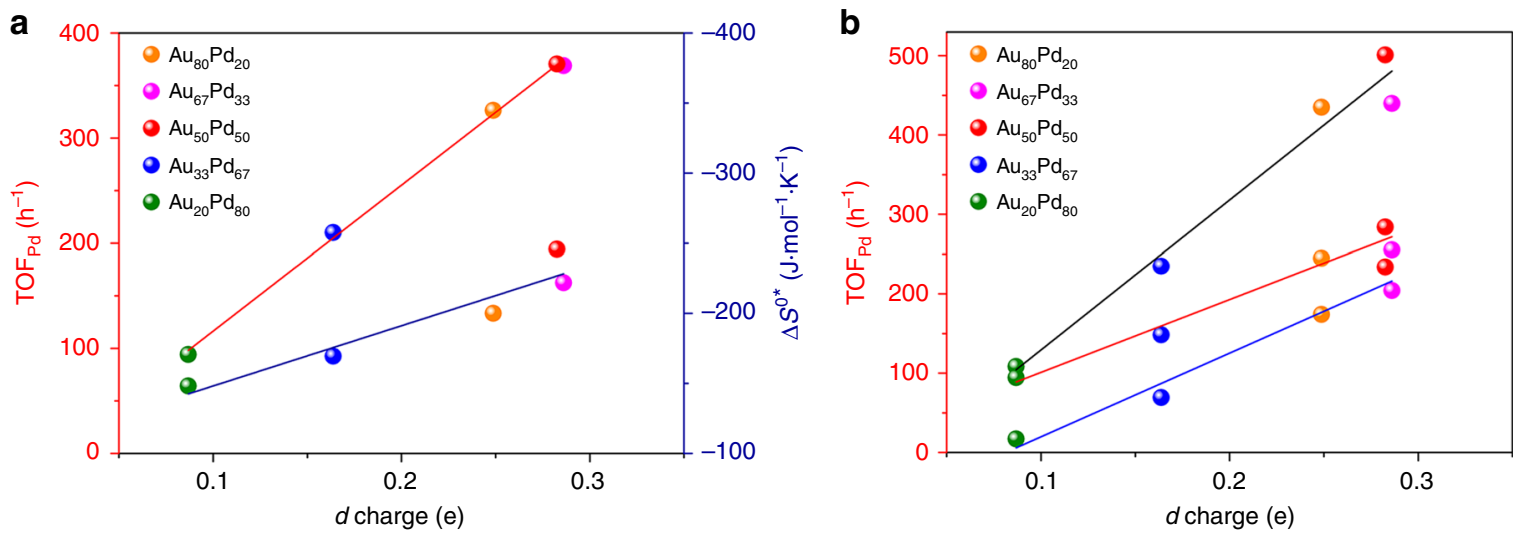

Fig. 6 Descriptor. a Relationship between the $d$-charge gain at Pd site and TOF ${ }_{P d}$ (red line) of the AuPd alloys, and the entropy of activation for the oxidation of benzyl alcohol to benzaldehyde $\left(\Delta S^{0^{\star}}\right.$, navy line). $\mathbf{b}$ Comparison of the TOF $\mathrm{Pd}_{\mathrm{d}}$ values of the nanocatalysts along with the compositions of the AuPd nanoalloys in the oxidations of 4-methylbenzyl alcohol (black line), 4-phenethyl alcohol (red line) and anisalcohol (blue line)

for the catalytic activity, the entropy change and $S$ with alloy compositions (Supplementary Fig. 23).

In summary, we have identified the $d$ charge at the Pd sites as a descriptor to predict entropy changes and activities in the oxidation of alcohols. The AuPd solid-solution nanoalloys confined by ordered mesoporous carbon with the detailed chemical, geometric and electronic structures at atomic level have been synthesized by the adsorbate mediated reduction and used to unambiguously determine the changing of the metal ligands of the surface palladium atoms. The maximum $d$-charge gain is obtained on the Pd single atom and dimer at approximate 33-50 at\% $\mathrm{Pd}$ in Au-Pd nanoalloy, which results in a pronounced improvement in the adsorption strength of primary alcohols, and therefore apparently higher aerobic oxidation activity and selectivity of primary alcohols under base-free conditions compared to those of an inert carbon-supported monometallic gold or lowactivity palladium catalyst. The experimentally measured $d$ charge on the transition metal sites, together with the DFT calculations on the nature of the adsorbing molecule and the demands which it makes, paves the way for the rational design and synthesis of bimetallic catalysts with tailored activities for wide catalytic applications, and the identification and tracking of key steps involved in the catalytic reactions.

\section{Methods}

Synthesis of AuPd alloys inside ordered mesoporous carbon. The synthesis involved the assembly of carbon precursors of low-molecular-weight phenolic resins, a silica source (tetraethylorthosilicate, TEOS, Acros Chemical Inc.), a gold source (chloroauric acid tetrahydrate, $\mathrm{HAuCl}_{4} \cdot 4 \mathrm{H}_{2} \mathrm{O},>99.9 \mathrm{wt} \%$, Sigma-Aldrich), a palladium source $\left(\mathrm{PdCl}_{2}\right.$, palladium chloride solution, $5 \mathrm{wt} \%$ in $10 \mathrm{wt} \% \mathrm{HCl}$, Sigma-Aldrich Co.), a coordinating reagent (3-mercaptopropyltrimethoxysilane, MPTMS, $85 \mathrm{wt} \%$, Acros Chemical Inc.), and a structure directing agent (poly (ethylene oxide)-b-poly(propylene oxide)-b-poly(ethylene oxide) triblock copolymer F127, $\mathrm{EO}_{106} \mathrm{PO}_{70} \mathrm{EO}_{106}, M_{\mathrm{W}}=12,600 \mathrm{~g} \mathrm{~mol}^{-1}$, Acros Chemical Inc.) followed by an adsorbate mediated reduction. Typically, $4.16 \mathrm{~g}$ of TEOS and $3.94 \mathrm{~g}$ of MPTMS were pre-hydrolysed in the presence of $4.0 \mathrm{~g}$ of HCl $(0.2 \mathrm{M})$ and $20.0 \mathrm{~g}$ of ethanol for $30 \mathrm{~min}$ to obtain solution A. To a solution containing $6.4 \mathrm{~g}$ of Pluronic F127, $16.4 \mathrm{~mL}$ of $\mathrm{HAuCl}_{4}$ solution (gold concentration in ethanol: $48.5 \mathrm{mmol} \mathrm{L}^{-1}$ ), $7.2 \mathrm{~mL}$ of palladium chloride solution (palladium concentration in ethanol: 56.4 $\mathrm{mmol} \mathrm{L}^{-1}$ ), $4.0 \mathrm{~g}$ of preformed phenolic resins (Supplementary Methods) and 20.0 $\mathrm{g}$ of ethanol, solution A was added. The solution was stirred for $1 \mathrm{~h}$ at $40^{\circ} \mathrm{C}$, and then the mixture was transferred into evaporating dishes. The solvent evaporation was carried out in a hood at ambient temperature for $6 \mathrm{~h}$, and the resins were polymerized in an oven at $100^{\circ} \mathrm{C}$ for $24 \mathrm{~h}$. The as-prepared materials were obtained by scraping the films from the dishes and refluxing the material in sulfuric acid with mechanical stirring ( $1.0 \mathrm{~g}$ of solid per $100 \mathrm{~mL}$ of $50 \mathrm{wt} \%$ sulfuric acid) at $90^{\circ} \mathrm{C}$ for $24 \mathrm{~h}$ to remove the triblock copolymer and pre-polymerize the resins. The resulting material was removed by filtration, washed with distilled water, and dried at $80^{\circ} \mathrm{C}$ under vacuum overnight. The as-prepared powders were transferred into a tubular furnace for reduction of the bimetallic material. The following heating programme was adopted. The temperature was increased from room temperature to $350^{\circ} \mathrm{C}$ at a rate of $1{ }^{\circ} \mathrm{C} \mathrm{min}-1$, increased to $600{ }^{\circ} \mathrm{C}$ at a rate of $5^{\circ} \mathrm{C} \mathrm{min}-1$, and then held for $3 \mathrm{~h}$. After cooling to room temperature under protect by $\mathrm{N}_{2}$ atmosphere, the black powders were treated at $180^{\circ} \mathrm{C}$ in an oven in air. Then, the obtained composite catalysts were named $\mathrm{Au}_{x} \mathrm{Pd}_{y}$, wherein $x$ and $y$ represent the $\mathrm{Au} /(\mathrm{Au}+\mathrm{Pd})$ and $\mathrm{Pd} /(\mathrm{Au}+\mathrm{Pd})$ values in molar percentages in the mother liquor, respectively. The loadings of $\mathrm{Au}$ and $\mathrm{Pd}$ in the nanocatalysts are estimated by the EDX mapping analysis in the TEM mode. It reveals that the total amount of metals is $\sim 2.8-3.6 \mathrm{wt} \%$ for all catalysts and both the amounts and the Au:Pd ratios are close to the theoretical values (Table 1, Supplementary Fig. 5).

For comparison, monometallic $\mathrm{Au}$ and $\mathrm{Pd}$ and metal-free carrier (ordered mesoporous carbonaceous carrier (OMCC)) were synthesized according to the described processes with the indicated total metal molar contents or in the absence of metal. The specific surface area $\left(S_{\mathrm{BET}}\right)$, pore size $\left(D_{\mathrm{p}}\right)$, and pore volume $\left(V_{\mathrm{t}}\right)$ is $417 \mathrm{~m}^{2} \mathrm{~g}^{-1}, 6.6 \mathrm{~nm}$ and $0.49 \mathrm{~cm}^{3} \mathrm{~g}^{-1}$, respectively.

Characterization of the materials. The XRD measurements were taken using a Rigaku Dmax-3C diffractometer ( $\mathrm{Cu} \mathrm{K}$ radiation). Structural investigations of the catalysts were performed on a JEM 2100 microscope operated at $200 \mathrm{kV}$ and an FEI Tecnai G2 F30 microscope equipped with a high-angle annular dark-field scanning transmission electron microscopy (HAADF-STEM) detector in TEM and STEM modes. The elemental analyses of the spots, lines and areas selected in the HAADFSTEM images were performed using a Philips EDX instrument. The EDX spectra were obtained in STEM mode with a focused electron beam in the sub-nanometre range. The EDX spectra were collected from $\sim 20$ nanoparticles in different areas. The AC-STEM images were performed using a JEM-ARM $200 \mathrm{~F}$ microscope operated at $200 \mathrm{kV}$. An ultrathin sectioning technique was applied to prepare ultrathin sections by embedding the sample in LR White acrylic resin (hard) and sectioning on an ultramicrotome. The thin sections $(\sim 80 \mathrm{~nm})$ were supported on 300 -mesh copper grids. $\mathrm{N}_{2}$ physisorption isotherms were recorded at $77 \mathrm{~K}$ with a Micromeritics TriStar II 3020 analyser using the BET method to estimate the specific surface areas $\left(S_{\mathrm{BET}}\right)$ and the Barrett-Joyner-Halenda $(\mathrm{BJH})$ model to derive the pore volumes and pore size distributions. The real-time UV-Vis spectra were obtained using a UV-Vis spectrophotometer (Varian Cary 100). A Varian VISTAMPX inductively coupled plasma-atomic emission spectrometry (ICP-AES) instrument was used to determine the gold and palladium loadings. The XPS measurements were recorded on a Perkin-Elmer PHI 5000CESCA system. The samples were evacuated in a Load lock chamber and then transferred to the analysis chamber $\left(10^{-9} \mathrm{mbar}\right)$. The $\mathrm{C} 1 \mathrm{~s}$ peak was adopted as an internal standard for the determination of the peak positions and was corrected to $284.6 \mathrm{eV}$. The $\mathrm{Au}$ and Pd binding energies were fitted by peak fitting techniques. Thermal analysis (TGDTA) measurements were performed on a Mettler-Toledo TG/SDTA 851e apparatus. Samples were heated from $25^{\circ} \mathrm{C}$ to $800^{\circ} \mathrm{C}$ at a rate of $10^{\circ} \mathrm{C} \mathrm{min}-1$ with nitrogen flowing at a rate of $50 \mathrm{~mL} \mathrm{~min}^{-1}$. Upon heat treatment of the as-prepared material, the TG curves revealed that approximately $48 \mathrm{wt} \%$ residue solid remained (Supplementary Fig. 24). The theoretical metal contents were thus roughly estimated by the adding amounts of metal assuming none of the mass lost during thermal reduction was from the metals (Table 1). TPDe measurements were made on a Micromeritics Auto Chem II 2920 instrument coupled to a well-calibrated Microvision 2 quadrupole mass spectrometer (MKS Instruments Cirrus II). Prior to the TPDe measurements, the sample (ca. $50 \mathrm{mg}$ ) was purged at $50^{\circ} \mathrm{C}$ for $1 \mathrm{~h}$ with flowing dry $\mathrm{He}\left(40 \mathrm{~mL} \mathrm{~min}^{-1}\right.$, > 99.999\%). The purging temperature was then increased to $800{ }^{\circ} \mathrm{C}$ at a rate of $10^{\circ} \mathrm{C} \mathrm{min}-1$, and dry $\mathrm{He}$ continued to flow at a rate of $40 \mathrm{~mL} \mathrm{~min}-1$. Fragments with mass-to-charge $(\mathrm{m} / \mathrm{z})$ ratios of $16,18,28,44$, and 64 were observed ${ }^{67}$. 
$\mathrm{X}$-ray absorption spectra of the $\mathrm{Au}_{3}$-edge and Pd K-edge were conducted at the BL14W1 of the Shanghai Synchrotron Radiation Facility (SSRF). The samples were pressed into pellets and measured in fluorescence mode. A double-crystal Si (111) monochromator was used for energy selection at both the $\mathrm{Au} \mathrm{L}_{3}$-edge $(11,919 \mathrm{eV})$ and Pd K-edge $(24,350 \mathrm{keV})$. The $\mathrm{Au}$ and Pd EXAFS data of the same sample were processed simultaneously in $\mathbf{R}$-space using a software package for fitting of EXAFS data by fast Fourier inverse transform (IFEFFIT). The CN of $\mathrm{Pd}-\mathrm{Au}\left(\mathrm{CN}_{\mathrm{Pd}-\mathrm{Au}}\right)$ and $\mathrm{Au}-\mathrm{Pd}\left(\mathrm{CN}_{\mathrm{Au}-\mathrm{Pd}}\right)$ were fixed according to the equation (1) in the literature ${ }^{68}$ :

$$
\mathrm{CN}_{\mathrm{Pd}-\mathrm{Au}}=\frac{\chi_{\mathrm{Au}}}{\chi_{\mathrm{Pd}}} \mathrm{CN}_{\mathrm{Au}-\mathrm{Pd}}
$$

Where $\chi_{\mathrm{Au}} / \chi_{\mathrm{Pd}}$ is the atomic ratio of Au to Pd. The heterometallic bond distances and corresponding Debye-Waller factors were also constrained to be the same.

The binding energy shift $\Delta E_{\mathrm{B}}$ of the core level between pure metal and the alloy measured relative to the Fermi level in XPS experiments was related to changes of the Hartree-Fock one-electron energy of the core level, the change in the work function, and the final-state relaxation of a core hole between the metal and the alloy ${ }^{57}$. The calculation and results were shown in Supplementary Table 3.

All periodic spin-polarized DFT calculations were carried out using the Vienna Ab-initio Simulation Package (Supplementary Table 2).

Catalytic tests. The oxidation reactions were carried out in three-neck, roundbottom flasks. In a typical reaction, to a mixture of $5.0 \mathrm{mmol}$ of BA and $10 \mathrm{~mL}$ of deionized water, $32 \mathrm{mg}$ of powdered $\mathrm{Au}_{50} \mathrm{Pd}_{50}$ catalyst was added. The suspension was maintained in the presence of oxygen by an $\mathrm{O}_{2}$ balloon under atmospheric pressure, the stirring speed was fixed at $800 \mathrm{rpm}$ and the temperature was kept at $90^{\circ} \mathrm{C}$. Preliminary experiments performed by ranging stirring speeds from 400 to $1000 \mathrm{rpm}$ showed that the selected speed of $800 \mathrm{rpm}$ enabled the reaction to perform without diffusion limitations. The effect of mass transfer effect on the reaction rate was studied by varying the surface concentrations of metal but with similar dispersion, known as the Madon-Boudart (MB) test. Two additional samples with different total metal contents (1.28 and $1.84 \mathrm{wt} \%)$ were synthesized. These two samples showed similar XRD patterns, $\mathrm{N}_{2}$ sorption isotherm curves and TEM images with the studied $\mathrm{Au}_{50} \mathrm{Pd}_{50}$ catalyst (Supplementary Figs. 25-27). A linear relationship indicated the absence of mass transfer effect under present reaction conditions (Supplementary Fig. 13). The easy accessible of alloy nanoparticles intercalated into framework was related to the large-enough mesopores. Hot filtration was used at different time intervals to determine the BA conversion and metal leaching. Both the solid catalyst and aqueous mother liquor were extracted with ethyl acetate. The organic phases were combined and analysed to determine the conversion and yield by gas chromatography-mass spectrometry (GC-MS, 7890B-5977) or GC (Agilent 7890B) using a DB-Wax column. The solid catalyst was recovered for reuse by washing with water and drying at $80^{\circ} \mathrm{C}$ overnight under vacuum. The gas phase was analysed to determine the concentrations of $\mathrm{O}_{2}, \mathrm{CO}$ and $\mathrm{CO}_{2}$ by GC $(7890 \mathrm{~A})$ using a porapak $\mathrm{Q}$ column. The analysis was repeated at least three times with $\pm 5 \%$ experimental errors (standard deviation). The carbon balance for all tests was above $95 \%$. The oxidation was also carried out with 5.0 mmol of 4-methylbenzyl alcohol, 4-anisealcohol and phenylethyl alcohol.

The kinetic rate equation was deduced by considering that BA adsorbed on Pd and the mechanism for adsorbed alcohol dehydrogenation involved two consecutive dehydrogenation steps. A global kinetics constant $k$ was employed in the kinetics rate equation due to the fact that the first dehydrogenation of the bond scission of $\mathrm{O}-\mathrm{H}$ and the second dehydrogenation of the bond scission of $\mathrm{C}^{\alpha}-\mathrm{H}$ could not be measured independently. The TOF, activation energy $\left(E_{\mathrm{a}}\right)$, and entropy of activation $\left(\Delta S^{0^{*}}\right)$ were determined (Supplementary Fig. 16). The TOF value for each catalyst was calculated on the basis of the number of exposed palladium atoms, which was estimated on the similarities of the truncated octahedron shape of the nanoparticles (as evidenced in the AC-STEM image) and the homogeneous distribution in the alloy (Supplementary Fig. 16).

The recycling tests were carried out as following. Each time the catalyst was recycled, the oxidation reaction was performed under the same conditions. To ensure the same amount of catalyst was present during each cycle, multiple parallel tests were performed. The catalyst after the sixth run was referred to as $\mathrm{Au}_{50} \mathrm{Pd}_{50^{-}}$ R6. The aqueous solutions after each run were collected and combined to determine the metal leaching.

Solid mercapto-functionalized ordered mesoporous silica (SH-SBA-15, Supplementary Fig. 28) was used to trap the soluble metal species that had leached into solution. Typically, $49 \mathrm{mg}$ of SH-SBA-15 was added to the reaction flask prior to the addition of the reaction solution to give a molar ratio of SH:Pd $=35: 1$.

\section{Data availability}

The data that support the findings of this study are available from the corresponding author upon reasonable request.

Received: 26 November 2018 Accepted: 11 March 2019

Published online: 29 March 2019

\section{References}

1. Enache, D. I. et al. Solvent-free oxidation of primary alcohols to aldehydes using Au-Pd/TiO 2 catalysts. Science 311, 362-365 (2006).

2. Zhang, H. et al. Catalytically highly active top gold atom on palladium nanocluster. Nat. Mater. 11, 49-52 (2011).

3. Agarwal, N. et al. Aqueous Au-Pd colloids catalyze selective $\mathrm{CH}_{4}$ oxidation to $\mathrm{CH}_{3} \mathrm{OH}$ with $\mathrm{O}_{2}$ under mild conditions. Science 358, 223-227 (2017).

4. Gao, F. \& Goodman, D. W. Pd-Au bimetallic catalysts: understanding alloy effects from planar models and (supported) nanoparticles. Chem. Soc. Rev. 41, 8009-8020 (2012)

5. Nørskov, J. K., Bligaard, T., Rossmeisl, J. \& Christensen, C. H. Towards the computational design of solid catalysts. Nat. Chem. 1, 37-46 (2009).

6. Xin, H. et al. Effects of $d$-band shape on the surface reactivity of transitionmetal alloys. Phys. Rev. B 89, 115114 (2014)

7. Kitchin, J. R., Norskov, J. K., Barteau, M. A. \& Chen, J. G. Modification of the surface electronic and chemical properties of $\mathrm{Pt}(111)$ by subsurface $3 d$ transition metals. J. Chem. Phys. 120, 10240-10246 (2004).

8. Ferrando, R., Jellinek, J. \& Johnston, R. L. Nanoalloys: from theory to applications of alloy clusters and nanoparticles. Chem. Rev. 108, 845-910 (2008).

9. Zhang, B. \& Su, D. S. Probing the metal-support interaction in carbonsupported catalysts by using electron microscopy. ChemCatChem 7 , 3639-3645 (2015)

10. Marchal, R., Genest, A., Krüger, S. \& Rösch, N. Structure of Pd/Au alloy nanoparticles from a density functional theory-based embedded-atom potential. J. Phys. Chem. C. 117, 21810-21822 (2013).

11. Wang, D. et al. Single-phase bimetallic system for the selective oxidation of glycerol to glycerate. Chem. Commun. 0, 1956-1958 (2006).

12. Sankar, M. et al. Synthesis of stable ligand-free gold-palladium nanoparticles using a simple excess anion method. ACS Nano 6, 6600-6613 (2012).

13. Villa, A., Wang, D., Su, D. S. \& Prati, L. New challenges in gold catalysis: bimetallic systems. Catal. Sci. Technol. 5, 55-68 (2015).

14. Zafeiratos, S., Piccinin, S. \& Teschner, D. Alloys in catalysis: phase separation and surface segregation phenomena in response to the reactive environment. Catal. Sci. Technol. 2, 1787-1801 (2012).

15. Villa, A. et al. Characterisation of gold catalysts. Chem. Soc. Rev. 45, 4953-4994 (2016)

16. Liu, L. \& Corma, A. Metal catalysts for heterogeneous catalysis: from single atoms to nanoclusters and nanoparticles. Chem. Rev. 118, 4981-5079 (2018)

17. Hutchings, G. J. \& Kiely, C. J. Strategies for the synthesis of supported gold palladium nanoparticles with controlled morphology and composition. Acc. Chem. Res. 46, 1759-1772 (2013).

18. Evangelisti, C. et al. Bimetallic gold-palladium vapour derived catalysts: the role of structural features on their catalytic activity. J. Catal. 286, 224-236 (2012).

19. Pei, G. X. et al. Performance of Cu-alloyed Pd single-atom catalyst for semihydrogenation of acetylene under simulated front-end conditions. ACS Catal. 7, 1491-1500 (2017)

20. Feng, Q. et al. Isolated single-atom Pd sites in intermetallic nanostructures: high catalytic selectivity for semihydrogenation of alkynes. J. Am. Chem. Soc. 139, 7294-7301 (2017).

21. Dash, P. et al. Rational design of supported PdAu nanoparticle catalysts from structured nanoparticle precursors. J. Phys. Chem. C. 113, 12719-12730 (2009).

22. Liu, F., Wechsler, D. \& Zhang, P. Alloy-structure-dependent electronic behavior and surface properties of Au-Pd nanoparticles. Chem. Phys. Lett. 461, 254-259 (2008).

23. Okamoto, H. \& Massalski, T. The Au-Pd (gold-palladium) system. Bull. Alloy Phase Diagr. 6, 229-235 (1985)

24. Tian, S. et al. Carbon nitride supported $\mathrm{Fe}_{2}$ cluster catalysts with superior performance for alkene epoxidation. Nat. Commun. 9, 2353 (2018).

25. Christensen, A. et al. Phase diagrams for surface alloys. Phys. Rev. B 56 5822-5834 (1997).

26. Allison, E. G. \& Bond, G. C. The structure and catalytic properties of palladium-silver and palladium-gold alloys. Catal. Rev. 7, 233-289 (1972).

27. Marx, S. \& Baiker, A. Beneficial interaction of gold and palladium in bimetallic catalysts for the selective oxidation of benzyl alcohol. J. Phys. Chem. C. 113, 6191-6201 (2009).

28. Qi, B. et al. $\mathrm{L}_{2}$ and $\mathrm{L}_{3}$ measurements of transition-metal $5 d$ orbital occupancy, spin-orbit effects, and chemical bonding. Phys. Rev. B 36, 2972-2975 (1987).

29. Balcha, T. et al. Selective aerobic oxidation of crotyl alcohol using AuPd coreshell nanoparticles. ACS Catal. 1, 425-436 (2011).

30. Goetz, J. et al. Low-loaded palladium on $\alpha$-alumina catalysts: characterization by chemisorption, electron-microscopy, and photoelectron spectroscopy. J. Catal. 153, 86-93 (1995).

31. McCaulley, J. A. Temperature dependence of the Pd K-edge extended X-rayabsorption fine structure of $\mathrm{PdC}_{\mathrm{x}}$ (x 0.13). Phys. Rev. B 47, 4873-4879 (1993). 
32. Vojvodic, A., Nørskov, J. K. \& Abild-Pedersen, F. Electronic structure effects in transition metal surface chemistry. Top. Catal. 57, 25-32 (2014).

33. Lee, A. F. et al. Structural and catalytic properties of novel Au/Pd bimetallic colloid particles: EXAFS, XRD, and acetylene coupling. J. Phys. Chem. 99, 6096-6102 (1995).

34. Olovsson, W. et al. Core-level shifts in $f c c$ random alloys: a first-principles approach. Phys. Rev. B 72, 064203 (2005).

35. Duan, L. et al. Activation of Aryl Chlorides in Water under Phase-Transfer Agent-Free and Ligand-Free Suzuki Coupling by Heterogeneous Palladium Supported on Hybrid Mesoporous Carbon. ACS Catal. 5, 575-586 (2015).

36. Nascente, P. A. P., de Castro, S. G. C., Landers, R. \& Kleiman, G. G. X-ray photoemission and Auger energy shifts in some gold-palladium alloys. Phys. Rev. B 43, 4659-4666 (1991)

37. Mårtensson, $\mathrm{N}$. et al. Electron-spectroscopic studies of the $\mathrm{Cu}_{\mathrm{x}} \mathrm{Pd}_{1-\mathrm{x}}$ alloy system: chemical-shift effects and valence-electron spectra. Phys. Rev. B 24, 1725-1738 (1981).

38. Griffin, M. B. et al. The selective oxidation of ethylene glycol and 1,2propanediol on $\mathrm{Au}, \mathrm{Pd}$, and Au-Pd bimetallic catalysts. J. Catal. 307, 111-120 (2013).

39. Watson, R. E., Hudis, J. \& Perlman, M. L. Charge flow and $d$ compensation in gold alloys. Phys. Rev. B 4, 4139-4144 (1971).

40. Di, W. et al. In situ formation of Au-Pd bimetallic active sites promoting the physically mxed monometallic catalysts in the liquid-phase oxidation of alcohols. Chem. Eur. J. 16, 10007-10013 (2010).

41. Villa, A. et al. Au-Pd/AC as catalysts for alcohol oxidation: effect of reaction parameters on catalytic activity and selectivity. Appl. Catal., A 364, 221-228 (2009).

42. Fulvio, P. F. et al. "Brick-and-mortar" self-assembly approach to graphitic mesoporous carbon nanocomposites. Adv. Funct. Mater. 21, 2208-2215 (2011).

43. Wang, S. et al. Aggregation-free gold nanoparticles in ordered mesoporous carbons: toward highly active and stable heterogeneous catalysts. J. Am. Chem. Soc. 135, 11849-11860 (2013).

44. Zope, B. N., Hibbitts, D. D., Neurock, M. \& Davis, R. J. Reactivity of the gold/water interface during selective oxidation catalysis. Science 330, 74-78 (2010).

45. Rodrigues, E. G. et al. Influence of activated carbon surface chemistry on the activity of $\mathrm{Au} / \mathrm{AC}$ catalysts in glycerol oxidation. J. Catal. 281, 119-127 (2011).

46. Richardson, J. \& Jones, C. Strong evidence of solution-phase catalysis associated with palladium leaching from immobilized thiols during Heck and Suzuki coupling of aryl iodides, bromides, and chlorides. J. Catal. 251, 80-93 (2007).

47. Chen, S. et al. Poison tolerance to the selective hydrogenation of cinnamaldehyde in water over an ordered mesoporous carbonaceous composite supported Pd catalyst. ACS Catal. 7, 2074-2087 (2017).

48. van Bokhoven, J. J. G. M., Kuiper, A. E. T. \& Medema, J. The role of heterogeneity in the kinetics of a surface reaction: III. Distributions in activation enthalpy and entropy. J. Catal. 43, 181-191 (1976)

49. Villa, A. et al. Glycerol oxidation using gold-containing catalysts. Acc. Chem. Res. 48, 1403-1412 (2015).

50. Mallat, T. \& Baiker, A. Oxidation of alcohols with molecular oxygen on solid catalysts. Chem. Rev. 104, 3037-3058 (2004)

51. Boronat, M. et al. Mechanism of selective alcohol oxidation to aldehydes on gold catalysts: influence of surface roughness on reactivity. J. Catal. 278, 50-58 (2011).

52. Williams, R. M. \& Medlin, J. W. Benzyl alcohol oxidation on Pd(111): aromatic binding effects on alcohol reactivity. Langmuir 30, 4642-4653 (2014).

53. Hammond, C. et al. Direct catalytic conversion of methane to methanol in an aqueous medium by using copper-promoted Fe-ZSM-5. Angew. Chem. Int. Ed. 51, 5129-5133 (2012).

54. Hammond, C. et al. Catalytic and mechanistic insights of the low-temperature selective oxidation of methane over Cu-promoted Fe-ZSM-5. Chem. Eur. J. 18, 15735-15745 (2012).

55. Mariscal, M. M. et al. Nanoalloying in real time. A high resolution STEM and computer simulation study. Nanoscale 3, 5013-5019 (2011).

56. Wise, H. Activation entropy and electronic properties of metal catalysts. J. Catal. 10, 69-72 (1968).

57. Cho, E.-J. et al. Unoccupied states and charge transfer in $\mathrm{Cu}-\mathrm{Pd}$ alloys studied by bremsstrahlung isochromat spectroscopy, X-ray photoelectron spectroscopy, and $\mathrm{L}_{\mathrm{III}}$ absorption spectroscopy. Phys. Rev. B 52, 16443-16450 (1995).

58. Rowland, T., Cusack, N. E. \& Ross, R. G. The resistivity and thermoelectric power of the palladium-gold alloy system. J. Phys. F Met. Phys. 4, 2189-2201 (1974).
59. Petkov, V. et al. Surface atomic structure and functionality of metallic nanoparticles: a case study of Au-Pd nanoalloy catalysts. J. Phys. Chem. C. 121, 7854-7866 (2017).

60. Cui, X. et al. Bridging homogeneous and heterogeneous catalysis by heterogeneous single-metal-site catalysts. Nat. Catal. 1, 385-397 (2018).

61. Xie, S. et al. Enhancement in aerobic alcohol oxidation catalysis of $\mathrm{Au}_{25}$ clusters by single Pd atom doping. ACS Catal. 2, 1519-1523 (2012).

62. Therrien, A. J. et al. An atomic-scale view of single-site Pt catalysis for lowtemperature CO oxidation. Nat. Catal. 1, 192-198 (2018).

63. Marcinkowski, M. D. et al. Pt/Cu single-atom alloys as coke-resistant catalysts for efficient C-H activation. Nat. Chem. 10, 325-332 (2018)

64. Tu, W. \& Chin, Y. H. Catalytic consequences of the thermodynamic activities at metal cluster surfaces and their periodic reactivity trend for methanol oxidation. Angew. Chem. Int. Ed. 53, 12148-12152 (2014).

65. Chen, W. et al. Mechanistic and kinetic insights into the Pt-Ru synergy during hydrogen generation from ammonia borane over PtRu/CNT nanocatalysts. J. Catal. 356, 186-196 (2017).

66. Tu, W., Ghoussoub, M., Singh, C. V. \& Chin, Y. C. Consequences of surface oxophilicity of $\mathrm{Ni}, \mathrm{Ni}-\mathrm{Co}$, and Co clusters on methane activation. J. Am. Chem. Soc. 139, 6928-6945 (2017).

67. Yan, B., Tao, L.-Z., Liang, Y. \& Xu, B.-Q. Sustainable production of acrylic acid: catalytic performance of hydroxyapatites for gas-phase dehydration of lactic acid. ACS Catal. 4, 1931-1943 (2014).

68. Nashner, M. S. et al. Structural characterization of carbon-supported platinum-ruthenium nanoparticles from the molecular cluster precursor $\mathrm{PtRu}_{5} \mathrm{C}(\mathrm{CO})_{16}$. J. Am. Chem. Soc. 119, 7760-7771 (1997).

\section{Acknowledgements}

This work was supported by the National Natural Science Foundation of China (21773156, 21503136), the Ministry of Education of China (PCSIRT_IRT_16R49), the International Joint Laboratory on Resource Chemistry of China (IJLRC), the Shanghai Sci. \& Tech. and Edu. Committee (17JC1404200) and the Shanghai Gaofeng \& Gaoyuan Project for University Academic Program Development.

\section{Author contributions}

Y.W. designed the research, supervised experiments, and edited the manuscript. X.Z., Q.G. and Y.S. synthesized the alloy catalysts, performed the structural characterization and catalytic tests, analysed the XAS and kinetics data, and wrote the manuscript. S.C analysed the XPS data, performed the TG and TPD characterizations and edited the figures. J.W. performed the XAS experiments and data analysis. M.W. performed the catalytic tests. Y.T., W.F., X.D. and D.C. contributed to the DFT calculations and discussion on the kinetics. All authors discussed the results and commented on the manuscript.

\section{Additional information}

Supplementary Information accompanies this paper at https://doi.org/10.1038/s41467 019-09421-5.

Competing interests: The authors declare no competing interests.

Reprints and permission information is available online at http://npg.nature.com/ reprintsandpermissions/

Journal Peer Review Information: Nature Communications thanks Feng Gao, and other anonymous reviewer(s) for their contribution to the peer review of this work. Peer reviewer reports are available.

Publisher's note: Springer Nature remains neutral with regard to jurisdictional claims in published maps and institutional affiliations.

Open Access This article is licensed under a Creative Commons Attribution 4.0 International License, which permits use, sharing, adaptation, distribution and reproduction in any medium or format, as long as you give appropriate credit to the original author(s) and the source, provide a link to the Creative Commons license, and indicate if changes were made. The images or other third party material in this article are included in the article's Creative Commons license, unless indicated otherwise in a credit line to the material. If material is not included in the article's Creative Commons license and your intended use is not permitted by statutory regulation or exceeds the permitted use, you will need to obtain permission directly from the copyright holder. To view a copy of this license, visit http://creativecommons.org/ licenses/by/4.0\%

(C) The Author(s) 2019 